\title{
Digerindo o indigesto: a escatologia política do Vomitaço
}

\author{
Viktor Chagas' \\ https://orcid.org/0000-0002-1806-6062 \\ I - UFF \\ Rio de Janeiro (RJ), Brasil
}

Resumo: O presente artigo procura discutir o Vomitaço como uma experiência de ação conectiva disruptiva de ciber-protesto. Vomitaço é o nome de uma ação organizada, que consiste na publicação de comentários nas páginas de alvos com um sticker representando um personagem vomitando. A manifestação se popularizou durante o desenrolar do processo de impeachment sofrido por Dilma Rousseff. O ensaio debate o lugar que ocupa o Vomitaço no cenário do ativismo político nacional, e conta com dados provenientes da etnografia combinada com entrevistas em profundidade e observação de estatísticas de acesso à página do movimento no Facebook.

Palavras-chaves: internet e política; ciberativismo; Vomitaço.

Abstract: Digesting the indigestible: the political scatology of the Vomitaço - The present article aims to discuss the Vomitaço [super puke] as a connective disruptive action of cyber-protest. Vomitaço is the name of an organized action, which consists in publishing comments on targets' posts with a puke sticker. The demonstration became popular during the impeachment process of Dilma Rousseff. The essay debates the place occupied by Vomitaço in the national political scenario, and brings data from an ethnographic approach, combined with in-depth interviews and statistics from the fanpage of the movement in Facebook.

Keywords: internet and politics; cyberactivism; Vomitaço.

Comparações entre a militância política e as torcidas organizadas têm sido frequentes nos últimos meses, em função da intensa cobertura noticiosa acerca do impeachment da presidenta Dilma Rousseff (CHAGAS, 2016; ALVES, 2016). Nas conversas cotidianas, evoca-se nostalgicamente o pretenso imaginário do brasileiro cordial para explicar uma propalada situação de decadência moral pela qual o país atravessaria. Fruto desta 
decadência são as manifestações de ódio e agressividade nas ruas, e, principalmente, nas redes sociais online, que têm marcado o posicionamento político de diferentes grupos. Misto de ofensa e protesto bem-humorado, o "Vomitaço" ganhou notoriedade nesse contexto, no calor da votação pela admissibilidade do processo de afastamento da presidenta pelo Senado.

Vomitaço é o nome de uma ação organizada, levada a efeito a partir do Facebook, que consiste na publicação repetida e ordenada de comentários nas páginas de seus alvos com um sticker que representa um personagem vomitando. A manifestação rapidamente cresceu em volume e ganhou em organização. Trazemos abaixo algumas considerações sobre o significado do Vomitaço como ação política e desenvolvemos possíveis paralelos com outros tipos de ciber-comportamentos. Afinal, como podemos compreender este tipo de protesto? E em que medida podemos qualificar seus efeitos?

O texto se divide em quatro momentos. No primeiro deles, tratamos brevemente da conversação informal nos sistemas democráticos. Em seguida, procuramos discutir o comportamento troll; e, depois, o papel do protesto disruptivo no ambiente online. Por último, apresentamos o caso do Vomitaço e o que dele decorre.

\section{Jogando conversa fora: a política e a conversação informal na internet}

A leitura mais comum sobre o universo da política costuma reduzi-lo à esfera do poder e da tomada de decisão (MANSBRIDGE, 2009). A conversação informal é habitualmente legada a segundo plano, tratada como arena de baixo impacto no processo político (Schudson, 2008). Muito embora historicamente autores no campo da sociologia já tenham se ocupado de ressaltar o papel do cotidiano partindo de uma abordagem que advoga em prol de uma perspectiva dramática acerca da vida social (GOFFMAN, 2009[1956]; SCHUTZ, 1962), a teoria política ainda se debate em torno da importância da conversação e da discussão política (CARREIRO, 2017). A principal crítica segue sendo a de que, no que tange à conversa informal sobre a política, seus resultados são reconhecidos como coletivos e de longo prazo apenas, inscritos no circuito da cultura política.

As mudanças produzidas por alterações no sistema cultural da política, como afirma Goldfarb (2012), são percebidas gradualmente, e, por essa razão, tem-se a falsa impressão de que esses resultados coletivos são simplesmente nulos. Mansbridge (2009, p. 209-211) atesta que a conversação cotidiana é o espaço do "ativismo dos não-ativistas" e que, como ação política, distingue-se da deliberação pública em assembleias na medida em que é pensada como fim em si mesma, enquanto a última é tomada como meio para a ação em si.

O ambiente das mídias sociais tem apresentado questões que confrontam a posição conservadora dos cientistas políticos a esse respeito. Desse modo, a conversação informal tem se alimentado da brecha aberta por sistemas de interação online, elevando, por sua vez, a discussão política ao patamar do corriqueiro. 
Muito se discute a respeito do papel desempenhado pela internet, de modo geral, no cenário político. O debate tem priorizado o entendimento de que, se por um lado, autores insistem em reconhecer no elemento tecnológico um favorecedor da participação direta do cidadão comum frente à política, por outro, há quem defenda que os dispositivos interativos, ao contrário, contribuem para estabelecer uma distância mais firme e acentuada entre o eleitor e seu representante, a partir de uma barreira mediática (STROMER-GALLEY, 2013; cf. tb. MARQUES, 2016). De um modo ou de outro, a conversação entre político e cidadão comum ou entre o cidadão e os seus iguais, se não como parte efetiva das arenas decisórias, pode ter impacto a partir do que Mansbridge (2009, p. 211) qualifica como "micro-negociações" do cotidiano, uma situação tal em que "mesmo um parceiro que não fala pode moldar o que o outro diz através de uma indicação não verbal de entendimento ou confusão, interesse ou enfado". Entendendo este tipo de manifestação como "ato político", Mansbridge alega que lutas individuais podem se conectar a causas coletivas ou lutas normativas mais amplas e abrangentes, quando enxergadas como parte de um todo, isto é, no caldo cultural da política.

Dispondo sobre o que denomina uma "eu-pistemologia", Van Zoonen (2012) indica que as novas mídias desempenham papel importante na percepção dos indivíduos sobre seu próprio lugar na política. A autora comenta que os cidadãos conectados valorizam narrativas pessoais para traduzir experiências políticas, de tal modo que o debate público se converte em território de narcisismo político (PAPACHARISSI, 2011). Partindo de seus backgrounds pessoais e particulares, ao apresentarem suas convicções, os internautas reduzem o espaço do diálogo e da troca de informações e se atomizam, ao invés de fortalecerem suas posições.

Contrários à visão mais niilista do cenário contemporâneo, mas em acordo com os princípios levantados pelos advogados da tese do narcisismo político, Bennett e Segerberg (2012) contextualizam de outra maneira essas manifestações, classificando-as como ações conectivas. Tais ações são caracterizadas pelos autores (BENNETT, 2014) como uma resposta do público a uma "disfunção democrática", em que prevalece um sentimento de frustração generalizada com a política em uma paisagem na qual o sistema eleitoral sucumbiu completamente ao marketing e aos interesses privados.

A principal diferença da ação conectiva em relação à ação coletiva tradicional, porém, é que a primeira trata-se de uma mobilização em larga-escala tomada a partir de expressões personalizadas da política, sem uma identificação ideológica ou coordenação exclusiva de uma liderança ou um grupo de lideranças políticas. As ações conectivas são dinâmicas emergentes, sustentadas por circuitos de comunicação mediática digital que articulam redes de ativistas para protestos físicos, como os ocorridos durante a Primavera Árabe, o 15M, o Occupy Wall Street ou mesmo as Jornadas de junho de 2013 no Brasil. Muitos destes protestos tiveram expressão nas ruas, após um período de incubação em mídias sociais como Twitter, Facebook, e Telegram. 
Como advoga Valenzuela (2014), para compreendermos os usos e efeitos das redes sociais online para o comportamento de protesto, precisamos saber distinguir entre os três eixos desta relação: a informação, a expressão de opiniões e o ativismo político propriamente dito. A conversação atua nestes três eixos, fomentando o engajamento casual do cidadão junto à política. Mais do que isso, ao estender a possibilidade e o alcance da troca de informações sobre a política, e da manifestação de opinião por parte do cidadão, a conversação online, em particular, contribui para que o debate público amplie sua circulação, a despeito da crítica de que ela não produziria efeitos reais.

A crítica, porém, é advinda de uma visão sobre o protesto e a desobediência civil relativamente estagnada no tempo. De acordo com Molly Sauter (2014, p. 27), em termos operacionais, a teoria sobre ações coletivas tem esbarrado no reconhecimento de que o espaço online é um ambiente que desenvolve novas práticas, mas, do ponto de vista teórico, os "ciber-protestos" se equivalem às manifestações físicas em ambiente real.

\section{Trollativismo, ciber-protestos e ações disruptivas em ambiente virtual}

Ainda não há clareza sobre o que sociologicamente caracterizaria um protesto político em ambiente online. Muitas são as ações politicamente orientadas na internet e na arena das mídias sociais que têm servido de objeto a diferentes investigações. Petições públicas (MARGETTS et al., 2013; ALDÉ \& SANTOS, 2012), experiências de gabinetes digitais e orçamentos participativos (COLEMAN \& SAMPAIO, 2016), e ainda outras formas de manifestação, normalmente encaradas com uma perspectiva crítica pela literatura, como "slack-tivism" ou "ativismo de sofá" (CHRISTENSEN, 2011; BREUR \& FAROOQ, 2012; BOULTON, 2015), são alguns dos estudos de casos destacados pela pesquisa científica recente. Mas o que o destaque dado pela mídia ${ }^{1}$ a uma intervenção artística como a do grupo Holograms for Freedom - que projetou uma passeata tridimensional fazendo uso de manifestantes virtuais apresentados por meio de hologramas nas ruas de Madrid, contra uma legislação anti-protestos do congresso espanhol -, parece supor é a existência de um fetiche no imaginário coletivo por "ciber-protestos" que espelhem manifestações físicas, não apenas em seus resultados, mas também em seus formatos.

Normalmente, as ações desempenhadas no ambiente virtual como forma de protesto se traduzem como ativismo disruptivo, e se assemelham em grande maneira ao que convencionalmente tratamos como desobediência civil. Elas estão mais baseadas na conduta e em ações performáticas em geral do que no ativismo inspirado no discurso (SAUTER, 2014, p. 30), e são favorecidas por um ambiente em que "microações" (MARGETTS et al., 2013) diminuem custos de participação, levando muitos autores a enxergarem falaciosamente este fenômeno como uma ação sem resultados práticos.

1 Cf. reportagens publicadas pelo Daily Mail <http://goo.gl/K11 hQh > e pelo El Mundo <http://goo.gl/TbWGNI >, para citar apenas dois. 
Protestos levados a efeito na internet invariavelmente evocam a figura do ativista hacker para justificar uma ética que lhe seria inerente. Os hackers, como lembra Gabriella Coleman (2012), são uma vertente ou subcultura de um grupo maior. Historicamente, a ética hacker é uma construção levada a efeito por indivíduos inseridos no movimento contracultural, especialmente na ficção literária e no cinema. Mas há outros grupos disputando espaço com os próprios hackers.

Coleman (2012) sugere que os phreackers, entusiastas amadores dos primórdios da computação e das telecomunicações, deram início a uma onda de transgressão na informática, invadindo e quebrando sistemas de segurança desde a década de 1950. Na sequência, a partir dos anos 1970, esses grupos se aliaram ao movimento contracultural e souberam aproximar suas práticas do espetáculo, o que contribuiu para uma certa glamurização do hacktivismo.

A popularização da internet, a partir dos anos 1990, trouxe uma outra figura à baila (COLEMAN, 2012, p. 101). Os trolls seguem à risca a tradição estética do espetáculo e da transgressão através da brincadeira, de tal modo que "é difícil decifrar e compreender a cultura política por trás de suas ações". Para Coleman, o comportamento troll é uma espécie de cortina-de-fumaça para o elitismo e a xenofobia resultantes da popularização da internet. É como se dissessem aos novatos "saiam daqui, esta é a nossa casa" (ibid, p. 113).

Phillips (2015) discorda em parte da autora quando aventa uma ética troll, segundo a qual estes personagens fariam suas brincadeiras apenas quando há questões que imbricam relações entre temas públicos e privados, como nos casos de celebrização e "romarias" virtuais em perfis memoriais de pessoas mortas, ou no já célebre caso de enfrentamento entre o grupo Anonymous e a Igreja da Cientologia que procurava censurar a exibição de uma entrevista com o astro Tom Cruise, em janeiro de 2008. Jaakko Stenros (2015, p. 192-193), por outro lado, critica a postura dos trolls, comentando que a brincadeira opera como uma espécie de "bolha de proteção" para suas ofensas, e que este comportamento "obriga os outros a brincarem sob suas próprias regras".

Nesse sentido, o papel da polidez na conversação online, tal como destacado por Recuero (2012, p. 160), é essencial. A polidez não é apenas um instrumento de organização da conversação, mas de normatização do contexto, diz a autora. É exatamente por confiar na relação intrínseca entre polidez e cooperação entre os atores participantes da conversação que um comportamento disruptivo pode expressar desagrado e protesto.

Para Coleman (2012), os trolls são descendentes diretos dos hackers, ainda que estes não sejam sua única referência ancestral. Segundo ela, a grande questão que deixam no ar é se suas ações são encenadas da forma como são por trapaça e ofensa pessoal ou apenas por uma diversão inconsequente (o lulz). O ativismo troll (ou trollativismo)² é, portanto, ainda uma incógnita no que diz respeito às suas motivações. Mas isso não significa que seja uma incógnita também no que diz respeito aos seus efeitos.

2 Em alguns meios, começa-se a falar em uma cultura ou estética trollpunk. Mais em: <http://goo.gl/PxAlij>. Acesso em: 20/03/2018. 


\section{O silêncio e a saturação da informação}

A história dos protestos em ambiente digital não é nenhuma novidade advinda do cenário das mídias sociais. Uma das ações mais empregadas como recurso similar a uma guerra de guerrilha nos ciber-ataques a grandes corporações dos anos 1990 é o chamado distributed-denial-of-service (DDoS), tática empregada originalmente por ciber-criminosos para derrubar sites e serviços online. Este tipo de ação se baseia em gerar um tráfego excessivo de dados através de requisições coordenadas em um intervalo muito curto de tempo, que instabilizam e inviabilizam o serviço alvo. É, como lembra Hoffman (2013), uma ação simples e eficiente.

Antes do DDoS, algoritmos de flooding já proporcionavam riscos à segurança de sistemas online. O flooding consiste em uma instrução de roteamento de dados em que cada pacote recebido por um determinado terminal é encaminhado a todas as saídas possíveis, o que gera um incremento no volume de dados circulantes em rede. A saturação (ou inundação, flooding) dos recursos de processamento desses serviços esgota suas capacidades e gera um enorme volume de tráfego de dados.

O DDoS, por sua vez, não requer uma grande largura de banda, podendo ser executado por um único terminal ou um pequeno grupo de terminais zumbi ${ }^{3}$, o que o torna ainda mais difícil de ser rastreado. Ele foi utilizado pela primeira vez em larga escala em 1999, contra um servidor de IRC da Universidade de Minnesota, que permaneceu por dias fora do ar (HOFFMAN, 2013). Logo em seguida, diferentes corporações, como Yahoo!, Amazon e eBay, sofreram ataques semelhantes. Mais recentemente, sites de operadoras de cartões de crédito, como Visa, Mastercard e o serviço de transferência de valores eletrônicos PayPal, foram alvos do coletivo Anonymous, após o bloqueio anunciado por essas empresas a doações para a conta do site Wikileaks (ibid., 2013).

Reapropriado pelo jargão das comunidades online, o flooding se tornou uma das táticas mais populares nas mãos dos trolls para incitar conflitos, as chamadas flaming wars $^{4}$. Em termos práticos, ações baseadas em táticas de flooding são executadas através de repetidas postagens idênticas, ocupando fóruns públicos, newsgroups ou BBSs e inviabilizando o diálogo. É uma anti-conversação.

Segundo Saulter, o que este tipo de ação demonstra é que, embora um argumento contra-intuitivo, "às vezes o que é necessário para o funcionamento continuado de um sistema democrático baseado na troca de informações e na conversação é a interpolação do silêncio, mais do que a injeção continuada de outras [...] falas" (2014, p. 20). É uma consideração semelhante à provocação do filósofo Nietzsche (1999) sobre o esquecimento, que ocuparia papel ativo ante o processo de seleção dos fatos e acontecimentos pela nossa memória. A saturação é o que dificulta a comunicação.

3 Terminais zumbi são computadores conectados à internet comprometidos por softwares maliciosos e dedicados a performar ações específicas controladas remotamente, como ataques, invasões etc.

4 Flaming é um comportamento hostil em ambientes públicos de comunidades online. Como o trolling, a ação é geralmente iniciada a partir de uma isca lançada pelo provocador. 
Utilizada como ferramenta para intervir em fóruns públicos, esta tática proporciona um espetáculo de desobediência à polidez (ou à chamada netiqueta). Ao não reconhecerem protestos disruptivos na internet como "conduta válida politicamente", porém, os críticos dessas ações contribuem para definir de forma restritiva e artificial o que é uma "manifestação política aceitável" (SAUTER, 2014, p. 27; cf. tb. SMITH, 2016).

\section{Vomitar como gesto político}

OVomitaço se define como um movimento apartidário levado a efeito, em princípio, espontaneamente por internautas, sobretudo usuários do site de rede social Facebook. A ação consiste em publicar, em resposta a uma dada postagem na mídia social, o sticker "puke" (vômito) como comentário, para afirmar incômodo diante de uma determinada situação, especialmente relacionada a questões da esfera política nacional ${ }^{5}$.

Os stickers do Facebook foram introduzidos em 2013, e diferem dos conjuntos de emojis já incorporados pela ferramenta, pela sua variedade e descentralização na produção de seus sets, geralmente criados por diferentes designers espalhados pelo mundo sem um consórcio unificado que os represente ${ }^{6}$. O sticker "puke" foi desenhado por David Lanham para o set Meep, com inspiração nos mangás japoneses, e se tornou rapidamente um dos mais populares no Facebook, especialmente pela simplicidade das formas.

Como ação disruptiva, o gesto tem inspiração livre no episódio em que o deputado federal Jean Wyllys cuspiu no também deputado federal Jair Bolsonaro, após o último tê-lo ofendido durante a votação no plenário da Câmara pela admissibilidade do processo de impeachment, em 17 de abril de 2016. Alguns dias depois, em 22 de abril, o ator José de Abreu repetiu o gesto em um restaurante, de São Paulo, quando ofendido por um casal na mesa ao lado. No dia seguinte, em 23 de abril, artistas do coletivo Desvio realizaram uma performance no vão livre do Masp, em que cuspiram, defecaram e vomitaram em fotos de 38 políticos.

Estimulado por este cenário, o estudante de Comunicação Social L.P.M. decidiu manifestar-se na fanpage oficial do PMDB ao notar que o partido tecia loas ao então vicepresidente Michel Temer, apresentando-o como solução definitiva para o país, em meio à votação que decidiria pela abertura do processo de impeachment no Senado Federal. O estudante publicou então o que seria, nas suas palavras ${ }^{7}$, o primeiro "vômito", e notou, para seu espanto, que grande número de internautas fariam o mesmo, para sinalizar desagrado com as mensagens publicadas na página.

5 O "puke" não deve ser confundido com "puking rainbows" ("vomitando arco-íris" em tradução literal), uma expressão de otimismo diante de dificuldades. "Vomitar", no caso do Vomitaço, tem uma conotação desagradável, ainda que quem vomite o faça com prazer.

6 Emojis são pictogramas utilizados para expressar emoções em ambientes de comunicação textual, de modo similar aos emoticons. Os primeiros emojis pictóricos foram criados em 1999, visando à utilização em dispositivos móveis. Atualmente, diferentes sistemas operacionais e plataformas possuem seus próprios conjuntos de emojis, mas a adição de novas imagens é geralmente licenciada a partir do Consórcio Unicode, que reúne empresas privadas, órgãos públicos e universidades de vários países.

7 Autor e mais dois integrantes de seu grupo de pesquisa realizaram entrevista com os líderes do Vomitaço no dia 30 de junho de 2016. Os nomes de L.P.M. e M.M. foram mantidos em anonimato para atender à solicitação dos próprios informantes. 


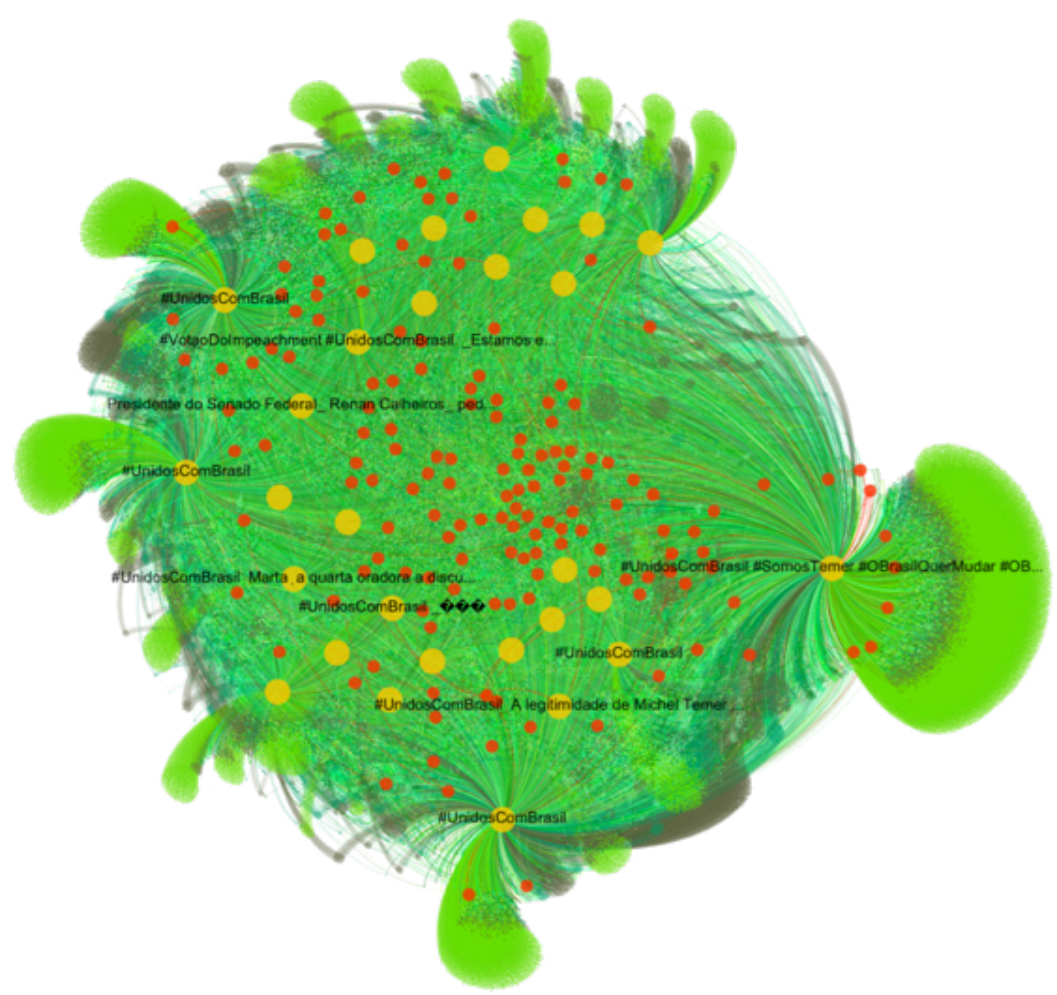

Fig. 1. Posts mais vomitados na fanpage do PMDB (11 e 12 de maio de 2016). Fonte: Elaboração própria.

Entre 11 e 12 de maio de 2016, foram mapeados, a partir da Graph API do Facebook, todos os comentários deixados na página institucional do PMDB. Tendo publicado 29 posts nesse período, a fanpage do partido recebeu um volume impressionante de comentários: 580 mil. Os dados foram então agrupados por posts e por usuários, de modo que se pudesse compreender a dinâmica da ação. Em seguida, foram isolados somente os comentários que apresentavam o sticker puke. O resultado, conforme apresentado na fig. 1, é um emaranhado de nós amarelos (os posts) ligados a outros nós (verdes e vermelhos ${ }^{8}$, os "vomitadores").

Em pouco mais de $48 \mathrm{~h}$ foram cerca de 540 mil comentários com o sticker. Dos outros 40 mil comentários que a fanpage recebeu nesse meio tempo, muitos eram ainda manifestações de repúdio em caráter verbal ou GIFs animados ${ }^{9}$ entre outros stickers que reproduziam o gesto de vomitar, dando origem a um processo de apropriação e reiteração de comportamentos que costumamos classificar como um meme de ação

8 Os nós em vermelho indicam os usuários que publicaram, no período mapeado, mais de 100 comentários com o sticker puke.

9 GIF, ou Graphics Interchangeable Format, é um formato de imagem largamente utilizado na internet. Para mais, cf. Eppink (2014). 
popular (CHAGAS et al., 2017; SHIFMAN, 2014). A ação paralisou os esforços de moderação da equipe de mídias sociais do PMDB, tornando difícil até mesmo excluir os comentários ou bloquear os usuários que atuavam em enxame.

O post mais "vomitado", por exemplo, marcado com as hashtags \#UnidosComBrasil, \#SomosTemer, \#OBrasilQuerMudar e \#OBrasilVaiMudar, recebeu sozinho mais de 115 mil "vômitos". O internauta que liderou o movimento "vomitou" 768 vezes em diferentes posts. Mas ele não é, definitivamente, caso isolado. Sete outros internautas "vomitaram" pelo menos 300 vezes e exatos 161 internautas "vomitaram" mais de 100 vezes nos mesmos 29 posts.

Diante do sucesso da ação, o Vomitaço levou menos de 24h para se "institucionalizar", a partir da decisão de L.P.M. e M.M. de criar uma página própria no Facebook com um contorno mais organizado para centralizar as campanhas futuras (fig. 2), o que gerou controvérsia entre os seus seguidores. Até 12 de setembro de 2016, quando a página do Vomitaço deixou de conduzir campanhas e passou somente a compartilhar links e comentar notícias, foram 46 ações coordenadas. O portfólio é extenso e envolve alvos como Eduardo Cunha, Sérgio Moro, Reinaldo Azevedo, Alexandre Frota, Jair Bolsonaro, entre outros, além de canais de mídia e programas televisivos, como GloboNews, IstoÉ, Fantástico e Jornal Nacional.

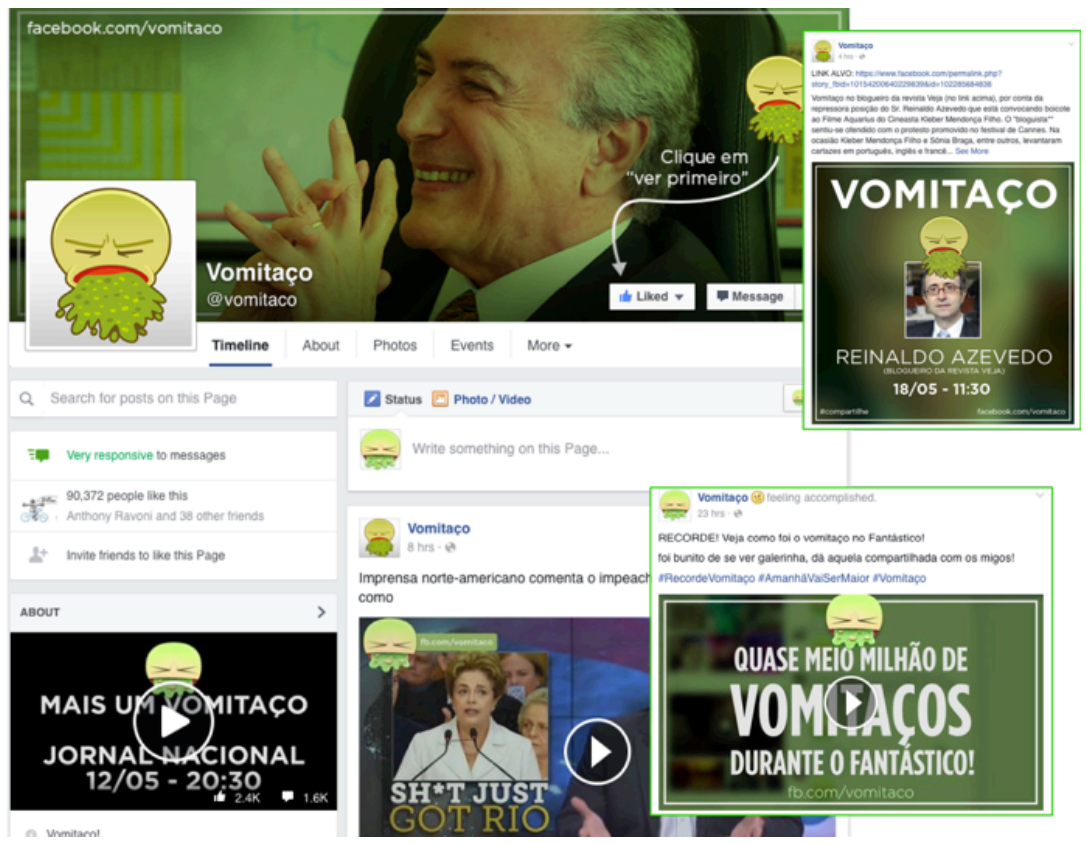

Fig. 2. Fanpage do Vomitaço. Fonte: Imagens da fanpage do Vomitaço. 
Os "vomitadores" estão geralmente antenados no noticiário político e cultural do país. O mapeamento que realizamos levantou 20 campanhas contra políticos, seis contra partidos, três contra agentes do judiciário, 18 contra canais de mídia e jornalistas, quatro contra personalidades e artistas, além de três outros, como anunciantes. As campanhas são capitaneadas pelos administradores da fanpage, que arregimentaram um exército de fiéis seguidores, dispostos a vomitar virtualmente nos alvos indicados (fig. 3).

No primeiro dia, a página do Vomitaço acumulou cerca de 4,9 mil fãs. No segundo, já eram 15 mil. Ao fim da primeira semana de atividades, a legião de vomitadores chegava a mais de 95 mil internautas. Hoje, são aproximadamente 170 mil seguidores, com um alcance médio de 287 mil pessoas no Facebook em todo o período ${ }^{10}$. No auge das campanhas, em junho e julho, o Vomitaço chegou a obter 4,5 milhões de usuários de alcance semanal, um feito.

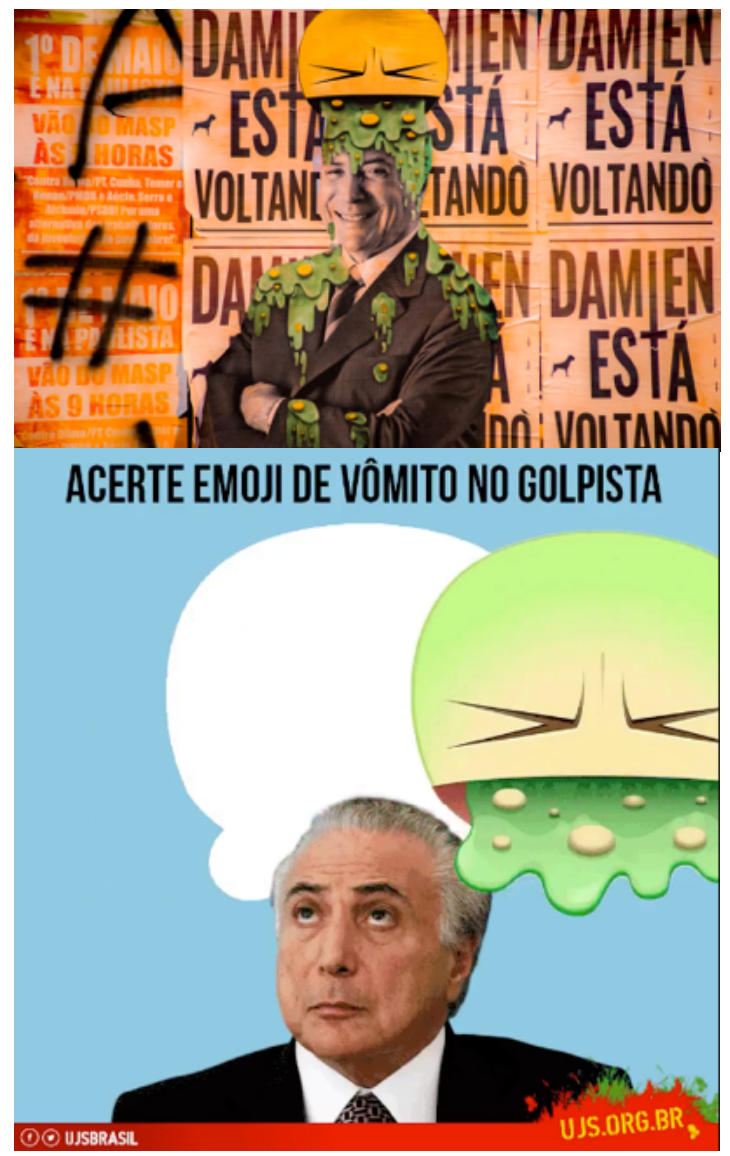

Fig. 3. Campanhas do Vomitaço.

Fonte: Imagens da fanpage do Vomitaço.

10 Os dados foram obtidos a partir do Facebook Insights. O acesso à plataforma foi franqueado pelos administradores aos pesquisadores do grupo, para fins acadêmicos. 
O volume surpreendente de contribuições de internautas de todo o país foi noticiado pelos principais meios de comunicação nacionais ${ }^{11}$ e internacionais ${ }^{12}$, e gerou mais interesse. Ainda em maio, um cartaz colado na Avenida Paulista trazia a imagem de Temer sob o sticker puke. Algumas semanas depois, um grupo ligado à União da Juventude Socialista (UJS) criou um game a partir de um GIF (fig. 4). E, assim, pouco a pouco, o movimento ocupou lugar no imaginário de resistência ao processo de impeachment.
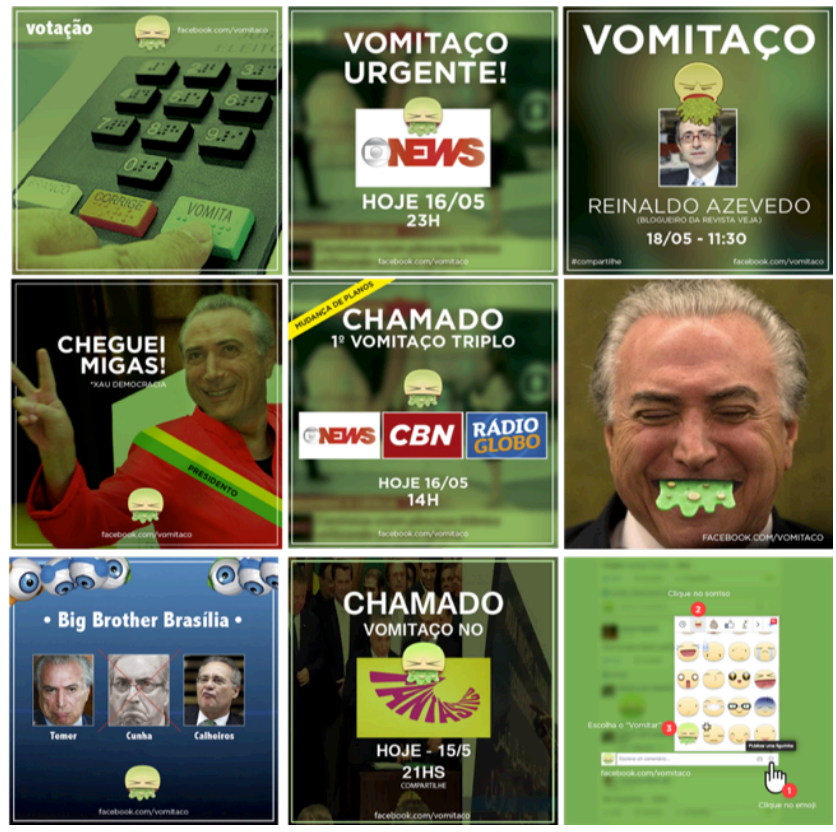

Fig. 4. Intervenções derivadas do Vomitaço.

Fonte: G1 <http://glo.bo/1NGJkd5> e UJS <http://gph.is/2gvPMrM>. Acesso em: 20/03/2018.

No dia $1^{\circ}$ de junho, o Vomitaço provou, pela primeira vez, do próprio veneno, ao promover uma ação contra o deputado federal Jair Bolsonaro. Seguidores do político, então, responderam com um "contra-vomitaço", publicando stickers com a figura de um coração azul na fanpage do movimento. O documentário do canal francês online de vídeos Spicee ${ }^{13}$ apresenta a situação como um empate técnico entre os dois grupos, mas L.P.M. e M.M. consideram uma vitória moral do Vomitaço na ocasião, já que a ação conta com muito menos seguidores que os fãs-militantes do adversário.

11 Cf. reportagens e colunas dos jornais O Globo <http://goo.gl/OZx2J8>, Estadão <http://goo.gl/k6ixGU>, da Revista Veja <http://goo.gl/YV5zGw>, e outros. Acesso em: 20/03/2018.

12 Cf. tb. reportagens da RFI < http://goo.gl/TkkQgT>, do portal Rue89 <http://goo.gl//Aqi1X>, do Washington Post $<$ https://goo.gl/qwDDBM>, e outros. Acesso em: 20/03/2018.

13 O mini-documentário foi publicado na íntegra no canal de vídeos Spicee em versão somente para assinantes. O trailler está disponível livremente no YouTube em: <https://goo.gl/HDJGz9>. Acesso em: 20/03/2018. 
Embora a página criada por L.P.M. e M.M. tenha mudado seu perfil de publicação com a consolidação do impeachment, em agosto de 2016, vomitaços continuam a ocorrer como ação espontânea em represália a diferentes posicionamentos discursivos assumidos por políticos e personalidades da mídia. Em 18 de agosto, o post que apresenta a foto de perfil da página do então candidato à presidência dos Estados Unidos pelo Partido Republicano, Donald Trump, originalmente publicada em 30 de março de 2012, foi também alvo de uma ação de flooding ${ }^{14}$. Diversos internautas contrários às posições do político publicaram frases em castelhano e stickers em defesa de mexicanos e latinos em geral, alvos de ataques xenófobos na campanha promovida por Trump. Inspirados ou não pelo Vomitaço, o fato é que a tática parece estar ganhando relevância como ação de ciber-dissidência.

Segundo Sauter (2014, p. 21), Thoreau e outros adeptos da desobediência civil compreenderam muito bem que sempre houve uma audiência para suas ações. Por essa razão, inclusive, se submeteram ao espetáculo da reação punitiva promovida pelo Estado. A punição, nesse entendimento, era a confirmação de que aquela manifestação fora tratada com seriedade e representava ameaça real à ordem estabelecida (Sauter, 2014).

O Vomitaço e seus correspondentes ainda não experimentaram repressão estatal à altura - ainda que, em novembro de 2016, o Governo Temer tenha ensaiado negociações com representantes do Facebook para tentar censurar a publicação do sticker ${ }^{15}$, o que só corrobora a sua eficácia enquanto ação política. A surpresa representada por estas ações obrigou gestores de mídias sociais a repensarem suas estratégias para moderação, e muitas campanhas de flooding têm sido combatidas com a deleção manual de comentários, quando não com robôs de censura prévia e automatizada. A grande vantagem desses guerrilheiros é o fato de se ancorarem em plataformas privadas de publicação, alheias aos confrontos políticos nacionais, e com grande fluxo de informações de outra natureza, especialmente as vocacionadas ao entretenimento. São espaços que Chadwick (2013) classifica como integrantes de um sistema mediático híbrido.

É o que Ethan Zuckerman (2008) procura explicar com a sua Teoria dos Gatos Fofos, segundo a qual a vocação primeira para a troca de informações voltadas ao entretenimento - como o grande volume de imagens de gatinhos fofos (os chamados LOLcats) compartilhadas por internautas de todo o mundo - em diversas mídias sociais gestadas por conglomerados privados possibilita a publicação dissimulada de conteúdos de natureza política e subversiva, que passam despercebidos por mecanismos de monitoramento implementados pelas autoridades públicas. Zuckerman (2008) e, na esteira dele, An Xiao Mina (2013), se refere, em particular, ao panorama vivenciado em regimes autoritários como a China. Mas o Vomitaço e seus congêneres provam que ações conectivas no ambiente das mídias sociais ganham contexto também em regimes nãoautoritários, como o Brasil e os Estados Unidos.

14 O post pode ser acessado diretamente em: <https://goo.gl/CjRFWK>. Acesso em: 20/03/2018.

15 Para mais detalhes, cf. <https://goo.gl/nmq7EV>. Acesso em: 28/03/2018. 
Mais do que isso, a Teoria dos Gatos Fofos nos ajuda a traçar um paralelo com o modelo desenvolvido por Robert Dahl (2005) para explicar as poliarquias, isto é, regimes com maior inclusão e participação políticas. De acordo com Dahl, quanto maior a tolerância à participação política, maior é o custo de repressão a ações organizadas. Isso significa que, em um ambiente onde a participação do internauta é valorada de forma positiva, o que gera evidentemente um fluxo de informações maior, é muito mais difícil prever, controlar e repreender ciclos de manifestações contrárias à ordem, como as ações de desobediência civil. O Vomitaço, é claro, se beneficia desta dificuldade para desenvolver suas campanhas.

\section{Digerindo o (indi)gesto...}

Os argumentos que procuramos desenvolver ao longo deste artigo buscavam responder às questões que inicialmente nos propusemos, sobre como poderíamos compreender os protestos realizados pelo Vomitaço, e de que forma poderíamos qualificar estas ações. Dado o caráter de permanente reformulação do movimento, ainda é complicado tecer considerações em definitivo.

Desde o final de 2016, a fanpage do Vomitaço não organiza mais campanhas contra alvos específicos. Seus administradores reformularam a linha editorial da página, passando apenas a compartilhar esporadicamente links sobre a conjuntura política nacional, sob o argumento de que era muito difícil e custoso centralizar as ações, já que eram apenas duas pessoas coordenando o movimento. De qualquer modo, o que esperamos ter elucidado com esta discussão é a característica do Vomitaço, e de táticas similares de flooding em plataformas de mídias sociais, de se apresentar como ações conectivas desenvolvidas nos moldes de um teatro de desobediência pública, que prevê uma audiência e, por isso, confia no potencial de circulação e repercussão de suas ações performatizadas. Em outras palavras, o Vomitaço pode ter perdido força à medida que se institucionalizou, mas a ação política coordenada, hoje, se vulgarizou. A própria cobertura midiática evidencia que vomitaços continuam a ocorrer, independentemente da coordenação empreendida pelos idealizadores do movimento ${ }^{16}$.

O Vomitaço é demonstração de que a livre manifestação da opinião pode ser exprimida através de uma não-manifestação ou de uma saturação dos canais de opinião que obstaculizam o próprio diálogo. Evocando o princípio tocquevilleano (TOCQUEVILLE, 1987), de acordo com o qual os prejuízos advindos da liberdade irrestrita de expressão podem ser plenamente apaziguados não pela censura e repressão, mas por uma liberdade

16 Basta observar que, mesmo com a página no Facebook desarticulada, o Vomitaço ganhou o noticiário político novamente em 2017, quando do escândalo da JBS. Entre maio e agosto daquele ano, o jornal O Globo atribuiu grande ênfase às ações espontâneas dos internautas na página pessoal de Temer, cf. p.ex. <https://glo. bo/2LPPyXX > e < https://glo.bo/2PxgbmN $>$. A cobertura adversária assumida pela Rede Globo e seus veículos desde o episódio procurou destacar cada uma das manifestações virtuais contra o PMDB e seus aliados, com evidente objetivo de agendar a opinião pública a respeito da rejeição a Temer. 
ainda maior, o emprego de táticas de flooding como ação política nas mídias sociais parece apresentar dilema similar, guardadas as proporções, ao que historicamente a teoria política tem se confrontado, a respeito dos limites para as liberdades individuais face ao interesse público.

Se táticas de flooding e ataques de DDoS já eram comuns na internet de meados da década de 1990, há pelo menos um elemento novo a ser destacado nas ações do Vomitaço: elas são ações políticas calcadas em uma lógica estrita da sociabilidade em rede. Diferentemente do DDoS, em que se tem um ataque orquestrado e performado por robôs, ou das flame wars em fóruns online, em que grupos rivais articulados se confrontam, o Vomitaço é uma ação levada a efeito pela participação espontânea e "descoordenada" de internautas casuais (ALDÉ, 2011), tragados por um desejo intenso de externar sua repulsa e pelo baixo custo de participação para tanto. Por mais que o movimento tenha passado por um período de institucionalização, com lideranças definindo os rumos das ações e os alvos das campanhas, a caracterização do Vomitaço segue em disputa por grupos apócrifos, não necessariamente vinculados aos seus idealizadores. Esses grupos se apropriam do humor e do caráter de brincadeira política (BENNETT, 1979) para expressar sua resistência. Como espécie de ciber-protesto que só é possível ocorrer no ambiente das mídias sociais, o Vomitaço se aproveita de um ecossistema constituído a partir de plataformas privadas (notadamente, neste caso, o Facebook) e da ludicidade evocada pela conversa informal no ambiente online (o uso de emojis, reações aos posts) para construir um modelo de ação política subversivo e de difícil repressão, que implica em danos claros aos adversários.

A título de curiosidade, para uma eventual próxima imersão, fica a deixa de M.M. a respeito de como enxerga o movimento que ele próprio capitaneou. Indagado sobre se se considera um terrorista virtual, o produtor responde que sim, para emendar na sequência que, caso o próprio Vomitaço sofresse um vomitaço, ele não hesitaria em banir os agressores e censurar os comentários contrários. A conversação informal sobre a política tem dessas vantagens: ela não se quer e não se requer coerente.

Viktor Chagas é professor do Departamento de Estudos Culturais e Mídia e do Programa de Pós-Graduação em Comunicação da Universidade Federal Fluminense (UFF). É bolsista CNPq de Pós-Doutorado Jr. na Universidade Federal da Bahia (UFBA), membro associado do Instituto Nacional de Ciência e Tecnologia em Democracia Digital (INCT.DD). É doutor em História, Política e Bens Culturais (CPDOC/FGV).

viktor@midia.uff.br 


\section{Referências}

ALDÉ, A. O internauta casual: notas sobre a circulação da opinião política na internet. In: Revista USP, São Paulo, n. 90, pp. 24-41, 2011.

ALDÉ, A.; SANTOS, J. G. B. Petições Públicas e Batalhas Digitais. In: XXI ENCONTRO DA COMPÓS, 2012, Juiz de Fora. Anais... Juiz de Fora: Compós, 2012.

ALVES, M. Coxinhas e petralhas: o fandom político como chave de análise da audiência criativa nas mídias sociais. In: Revista Geminis, São Carlos, v. 1 n. 7, pp. 117-146, 2016.

BENNETT, W. L. Connective action: the public's answer to democratic dysfunction. The conversation, 2014. Disponível em: <http://theconversation.com/connective-action-the-publics-answer-todemocratic-dysfunction-33089>. Acesso em: 20/03/2018.

BENNETT, W. L.; SEGERBERG, A. The logic of connective action. In: Information, Communication \& Society, Londres, v. 15 n. 5, pp. 739-768, 2012.

BENNETT, W. L. When politics becomes play. In: Political Behavior, Nova lorque, v. 1, n. 4, pp. 331-359, 1979.

BOULTON, C. In defense of "Slacktivism": how KONY 2012 got the whole world to watch. In: COOMBS, D. S.; COLLISTER, S. (org.). Debates for the Digital Age: the good, the bad and the ugly for our online world. Santa Barbara/Denver: Praeger, 2016.

BREUER, A.; FAROOQ, B. Online Political Participation: Slacktivism or Efficiency Increased Activism? Evidence from the Brazilian Ficha Limpa Campaign. In: ICA Annual Conference, 2012. Annals... San Diego: ICA, 2012.

CARREIRO, R. A discussão política em rede: um estudo sobre a divergência política no Facebook. Tese (Doutorado em Comunicação). Salvador: UFBA, 2017.

CHADWICK, A. The hybrid media system. Oxford: OUP, 2013.

CHAGAS, V. Sobre vaias: considerações acerca do jogo político (political game) e da brincadeira política (political play). In: CALABRE, L.; CABRAL, E. D. T.; SIQUEIRA, M.; FONSECA, V. In: Memória das Olimpíadas no Brasil: diálogos e olhares, vol. 1. Rio de Janeiro: Fundação Casa de Rui Barbosa, 2017.

CHAGAS, V. et al. A política dos memes e os memes da política: proposta metodológica de análise de conteúdo de memes dos debates eleitorais de 2014.In: Intexto, Porto Alegre, n. 38, pp. 173-196, 2017.

CHRISTENSEN, H. S. Political activities on the Internet: Slacktivism or political participation by other means? In: First Monday, Chicago, v. 16 n. 7, 2011.

COLEMAN, G. Phreaks, hackers, and trolls: the politics of transgression and spectacle. In: MANDIBERG, M. The social media reader. New York: NYU Press, 2012.

COLEMAN, S.; SAMPAIO, R. C. Sustaining a democratic innovation: a study of three e-participatory budgets in Belo Horizonte. In: Information, Communication \& Society, Londres, v. 20 n. 5, pp. 754-769, 2017.

DAHL, R. Poliarquia: participação e oposição. São Paulo: Edusp, 2005.

EPPINK, J. A brief history of the GIF. In: Journal of Visual Culture, Thousand Oaks, v. 13 n. 3, pp. 268-306, 2014.

GOFFMAN, E. A representação do eu na vida cotidiana. Petrópolis: Vozes, 2009.

GOLDFARB, J. Reinventing political culture. Londres: Polity, 2012.

HOFFMAN, S. DDoS: A Brief History, Part I \& Part II. In: Fortinet, março de 2013. Disponível em: $<$ https://blog.fortinet.com/2013/03/25/ddos-a-brief-history>. Acesso em: 20/03/2018. 
MANSBRIDGE, J. A conversação cotidiana no sistema deliberativo. In: MARQUES, A. C. S. (org.). A deliberação pública e suas dimensões sociais, políticas e comunicativas. Belo Horizonte: Autêntica, 2009.

MARGETTS, H.; et al. Leadership without leaders? Starters and followers in online collective action. In: Political Studies, Thousand Oaks, v. 63 n. 2, pp. 278-299, 2013.

MARQUES, F. P. J. Ciberpolítica: conceitos e experiências. Salvador: Edufba, 2016.

MINA, A. X. Batman, Pandaman and the Blind Man: a case study in social change memes and Internet censorship in China. In: Journal of Visual Culture, Thousand Oaks, v. 13 n. 3, pp. 359-375, 2013.

PAPACHARISSI, Z. The virtual sphere 2.0: the internet, the public sphere, and beyond. In: CHADWICK, A.; HOWARD, P. Routledge Handbook of Internet Politics. Londres: Routledge, 2011.

NIETZSCHE, F. Da utilidade e desvantagem da História para a vida. In: Obras incompletas. São Paulo: Nova Cultural, 1999.

PHILLIPS, W. This is why we can't have nice things. Cambridge: MIT Press, 2015.

RECUERO, R. A conversação em rede: comunicação mediada pelo computador e redes sociais na internet. Porto Alegre: Sulinas, 2012.

SAUTER, M. The coming swarm: DDoS actions, hacktivism and civil disobedience. New York: Bloomsbury, 2014.

SCHUDSON, M. Why conversation is not the soul of democracy. In: Why Democracies Need an Unlovable Press. Cambridge: Polity, 2008.

SCHUTZ, A. On multiple realities. In: Collected Papers, vol. 1. Haia: Nijhoff, 1962.

SHIFMAN, L. Memes in digital culture. Cambridge: MIT Press, 2014.

SMITH, W. The boundaries of a deliberative system: the case of disruptive protest. In: Critical Policy Studies, v. 10 n. 2, pp. 152-170, 2016.

STENROS, J. Playfulness, play, and games: a constructionist lodology approach. Tampere: University of Tampere, 2015. (Tese de doutorado.)

STROMER-GALLEY, J. Interação online e por que os candidatos a evitam. In: MARQUES, F. P. J.; SAMPAIO, R. C.; AGGIO, C. Do clique à urna. Salvador: EdUFBA, 2013.

TOCQUEVILLE, A. de. Democracia na América. São Paulo: Itatiaia, 1987.

VALENZUELA, S. Analisando o uso de redes sociais para o comportamento de protesto: o papel da informação, da expressão de opiniões e do ativismo. In: Revista Compolítica, Rio de Janeiro, v. 4 n. 1, pp. 13-52, 2014.

VAN ZOONEN, L. I-Pistemology: changing truth claims in popular and political culture. In: European Journal of Communication, Thousand Oaks, v. 27 n. 1, pp. 56-67, 2012.

ZUCKERMAN, E. The Cute Cat Theory Talk at ETech. In: My Heart's in Acra, março de 2008. Disponível em: <http://www.ethanzuckerman.com/blog/2008/03/08/the-cute-cat-theory-talk-at-etech/>. Acesso em: 13/03/2014.

Artigo recebido em 28/05/2018

e aprovado em 06/09/2018. 